\title{
SOBRE LA DISTINCIÓN ENTRE LO ÍNTIMO, LO PRIVADO Y LO PÚBLICO DE ERNESTO GARZÓN VALDÉS
}

\author{
Isabel Lifante Vidal \\ Universidad de Alicante
}

RESUMEN. El artículo analiza la distinción entre el ámbito de lo íntimo, lo privado y lo público trazada por Ernesto Garzón Valdés, poniendo de manifiesto la existencia de dos tipos de valoraciones implícitas en dicha caracterización: las relativas a la accesibilidad o divulgación de una conducta, y las relativas a la imposición de límites normativos a dicha conducta. A partir de ahí, y centrándose exclusivamente en el primer tipo de cuestiones, propone una manera alternativa de caracterizar el ámbito de lo íntimo, lo privado y lo público.

Palabras clave: Ernesto Garzón Valdés, ámbito íntimo, ámbito privado, ámbito público.

ABSTRACT. This article analyses the distinction that Ernesto Garzón Valdés draws between the intimate, the private and the public spheres. It is remarked that in this characterisation two kinds of evaluative considerations are involved: those relative to the accessibility or publicity of a conduct, and those concerning the imposition of normative constraints to such a conduct. Starting from this point and focusing exclusively on the first kind of questions, the article proposes an alternative way to characterise the intimate, the private and the public spheres.

Keywords: Ernesto Garzón Valdés, intimate sphere, private sphere, public sphere. 


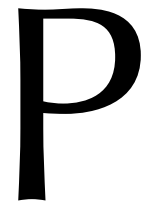

odríamos decir que apenas hay asunto de relevancia moral al que Ernesto GARZÓN VALDÉS no haya aportado algún análisis esclarecedor y sugerentes propuestas normativas. Éste es, obviamente, el caso de su trabajo «Algunos comentarios sobre lo íntimo, lo privado y lo público», publicado en la revista Claves, en $2003^{1}$, sobre el que aquí pretendo presentar unos breves comentarios. En ese trabajo, Ernesto GARZÓN pretende superar algunos de los problemas que plantea la clásica contraposición entre lo privado y lo público. Para ello propone introducir junto a estas categorías una tercera: la de lo íntimo; de modo que en su opinión deberían distinguirse tres ámbitos, y no sólo dos, en los que se podrían afectar los derechos o intereses de un individuo. Pretende así «demostrar que sí puede establecerse una distinción plausible entre lo íntimo, lo privado y lo público y que, en todo caso, la distinción entre lo privado y lo público es fundamental para determinar el alcance normativo de un sistema político-jurídico» ${ }^{2}$. Su objetivo es, por tanto, ofrecer elementos que nos ayuden a determinar con mayor precisión la evaluación moral de las conductas realizadas en estos ámbitos y, como consecuencia, nos permitan establecer criterios para la legitimación de la intervención de terceros, fundamentalmente la estatal, en cada uno de ellos.

Creo que esta tripartición aporta, tal y como pretende su autor, claridad conceptual, ayudando a superar muchos de los malentendidos originados por la tradicional contraposición entre lo privado y lo público, y le permite plantear sugerentes propuestas de cómo deben estar delimitados estos tres ámbitos para considerar legítimo un sistema político o jurídico. Lo que a continuación me propongo hacer en estas páginas es simplemente presentar unas breves reflexiones sobre el modo en que estas tres categorías son trazadas por Ernesto GARZÓN, y a partir de ellas plantear algunas dudas y sugerencias originadas por la lectura de este concreto trabajo.

Recordemos la caracterización que Ernesto GARZÓN realiza en su artículo de estos tres ámbitos. Lo «íntimo» sería el ámbito tanto de los pensamientos de cada cual, de la formación de decisiones («lo aún no expresado y que probablemente nunca lo será»), como de aquellas acciones cuya realización no requiere la intervención de terceros y tampoco los afecta (que incluiría las acciones autocentradas o de tipo fisiológico). Éste sería, por tanto, un ámbito interno o autorreferente y que, como tal, —dice Ernesto GARZÓN- escaparía a la valoración moral. El ámbito de lo «privado» requiere necesariamente, a diferencia de lo íntimo, la presencia de por lo menos dos actores. Pero aun así, señala Ernesto GARZÓN, se trata del ámbito donde pueden imperar exclusivamente los deseos y preferencias individuales, como condición necesaria para el «ejercicio» de la libertad individual, conformando así —en palabras de Amartya SEN— la «esfera personal reconocida»; se trata — dice Ernesto GARZÓN- del «ámbito reservado para las relaciones interpersonales donde la selección de los participantes depende de la libre decisión de cada individuo». El ámbito de lo «público», por el contrario, se caracterizaría a partir de la idea de la libre accesibilidad de los comportamientos y decisiones de las personas en sociedad, y englobaría «las cosas que pueden y deben ser vistas por cualquiera».

${ }^{1}$ GARZÓN VALDÉs, 2003: «Algunos comentarios sobre lo íntimo, lo privado y lo público», en Claves de razón práctica, n. ${ }^{\circ} 137$, pp. 14-24. Este trabajo a su vez es una versión posterior de un trabajo publicado en Doxa en 1998 (Ernesto GARZÓN VALDÉs, 1998: «Privacidad y publicidad», en Doxa, n. ${ }^{\circ}$ 21, vol. I, 1998: pp. 223-244).

${ }^{2}$ GARZÓN VALDÉs, 2003: p. 16. La cursiva es del autor. 
Como hemos dicho, el objetivo de Ernesto GARZÓN al delimitar conceptualmente estos ámbitos es determinar con mayor precisión el alcance de una posible evaluación moral o jurídica de los actos o actividades realizados en ellos, de cara fundamentalmente a legitimar la «intromisión» de terceros en dichas conductas. Sin embargo, y como el propio Ernesto GARZÓN reconoce, al menos para el caso de la distinción entre el ámbito privado y el público, la relación es en ocasiones la inversa: dependiendo de la evaluación que nos merecen esos actos, consideramos que pertenecen a uno u otro ámbito. Dicho en otros términos, estos conceptos no tienen un significado puramente descriptivo, sino también prescriptivo. Decir que una acción o actividad es privada o pública equivaldría a adscribirle normativamente este carácter y, por tanto, a considerar como legítima, o ilegítima, la libre accesibilidad a la misma.

Pero hemos de ser conscientes de que tal y como los define Ernesto GARZÓN, el primero de los ámbitos, el de lo íntimo, parece que queda «casi por cuestiones lógicas» fuera del alcance de valoraciones morales. Recordemos que lo íntimo sería el ámbito de los pensamientos, de la formación de las decisiones, así como de aquellas acciones cuya realización no requiere la intervención de terceros y tampoco los afecta. Por tanto, nunca estará justificada la afectación de este ámbito, ni la accesibilidad pública al mismo. Ésta es precisamente la tesis de Ernesto GARZÓN, quien acertadamente argumenta en contra de la justificación de cualquier posible «policía del pensamiento», que pretendiera precisamente invadir dicho ámbito ${ }^{3}$. Por lo que, en principio, podríamos decir que las categorías relevantes para la discusión acerca del establecimiento de límites a la acción o intervención social siguen siendo sólo dos: lo privado y lo público. A diferencia de lo que ocurre con la categoría de lo íntimo, considerar que algo se enmarca en la esfera de lo privado o de lo público es el resultado de haber hecho una valoración moral sobre la posibilidad de ser afectado por decisiones y/o acciones de terceros o del Estado. La cuestión seguiría siendo, por tanto, cómo delimitar el ámbito de lo privado, los límites del derecho a la privacidad, o dicho en otros términos, qué esfera es la que debe quedar excluida de la intromisión de terceros.

Ahora bien, quiero llamar la atención sobre la existencia en el trabajo de Ernesto GARZÓN de dos tipos de valoraciones distintas, ambas de gran relevancia, que aparecen entremezcladas en la caracterización de estas categorías. Por un lado, la valoración que nos puede merecer un acto o actividad (y ligado a ello, la valoración de la intromisión de terceros - especialmente el Estado- en el establecimiento de límites a dichas conductas); y, por otro lado, la valoración de la accesibilidad o posibilidad de divulgación de una conducta. La segunda valoración puede ser dependiente en alguna —o mejor dicho, en gran - medida de la primera, pero es importante darse cuenta de que son cuestiones distintas, y que no siempre tienen por qué coincidir. De modo paralelo, creo que cuando Ernesto GARZÓN habla en su trabajo de «traspasar» los límites de lo privado, esta expresión puede entenderse de dos maneras. La primera es equivalente a hacer accesible o publicitar la conducta, la segunda equivale a la posibilidad de introducir restricciones a las conductas realizadas en ese ámbito. Ernesto GARZÓN parece ocuparse de ambas, pues aunque en un primer momento podríamos pensar que la distinción se plantea a partir del primer sentido de esa expresión, una vez realizadas las

${ }^{3}$ GARZÓN VAldÉs, 2003: pp. 23-24. En este punto, el autor considera que «no es moralmente posible encontrar un equilibrio aceptable entre la inspección de la intimidad y la previsión y/o castigo de delitos». 
precisiones conceptuales, nuestro autor pasa a ocuparse también del segundo sentido, que es — podríamos decir — el más relevante para su objetivo de determinar «el alcance normativo de un sistema político-jurídico».

Debo advertir que las observaciones que siguen se van a centrar, sin embargo, exclusivamente en la primera de estas interpretaciones, es decir, en las cuestiones relativas a la caracterización de una conducta como pública, privada o íntima atendiendo a la cuestión de cuándo es legítimo hacer accesible o publicitar dicha conducta, y en este sentido, su alcance será bastante limitado, pues deja fuera toda la discusión sobre la legitimación de la imposición de límites a las conductas.

Pues bien, y aquí vendría mi sugerencia, creo que habría otra manera de caracterizar estos tres ámbitos de los que se ocupa Ernesto GARZÓN y que no relega el ámbito de lo íntimo a las acciones internas o autorreferentes; con ello se daría también cuenta de un uso de la expresión «intimidad» que va más allá de ese reducido ámbito en que la circunscribe nuestro autor. Para ello, necesitamos tomar en consideración dos criterios a la caracterización de esta clasificación. En primer lugar, el escenario (privado o público) en que se lleva a cabo una acción, y en segundo lugar, la existencia o no de relevancia social «legítima» de la conducta. El primero es por así decirlo «descriptivo», o al menos, más descriptivo que el segundo criterio, que sería plenamente «valorativo». Considerar que una conducta es socialmente relevante implica necesariamente llevar a cabo valoraciones sobre el contenido o los efectos de dicha conducta.

En este sentido, podemos pensar que nos encontramos con una ambigüedad de la expresión «privado». Un acto puede ser privado bien en el sentido de que se realiza en la intimidad, es decir en un escenario que consideramos «no público» (privado o doméstico), o bien en el sentido de que carece de relevancia social legítima. Y, del mismo modo, habría una ambigüedad de la expresión «público», que también puede referirse bien al escenario o ámbito en que se desarrolla una conducta, o bien a su relevancia social. Si esto es así, debemos considerar que no es incompatible decir que una determinada conducta se ha realizado en público, pero que por la ausencia de su relevancia social, debe tratarse como una conducta privada, en el sentido de que no consideramos legítima su divulgación... O por el contrario, es perfectamente posible considerar que una conducta que se ha realizado en un ámbito privado, dada su relevancia social, es lícito - e incluso necesario - que sea hecha pública, en el sentido de que se permita la accesibilidad o divulgación de la misma.

En este sentido podríamos seguir considerando la existencia de tres ámbitos de conducta. Un primer ámbito sería el de lo «íntimo», que englobaría aquello que hacemos (solos o en compañía) en un escenario privado y que carece de toda relevancia social. En este ámbito, como señala Ernesto GARZÓN, ninguna intervención o intromisión de terceros estaría justificada, siendo ilegítima su publicitación o divulgación. El ámbito de lo «privado» podría ser aquel que englobaría lo que hacemos en un escenario público (la calle, un bar...) pero que no tiene relevancia social y, por tanto, no debería ser legítima su divulgación, por mucho que sea realizado en un espacio de libre accesibilidad. Y, por último tendríamos el ámbito de lo público, aquello que ha de estar expuesto a la libre accesibilidad de las personas en sociedad, que sería el ámbito de aquellos actos que - realizados bien en espacios públicos, bien en espacios privados- poseen relevancia social legítima. Por supuesto, para determinar en qué casos se da esta legítima 
relevancia social, necesitaremos acudir a valoraciones normativas de las del tipo que Ernesto GARZÓN realiza en su trabajo para considerar los casos en los que es legítimo la imposición de límites normativos a las conductas y que se han quedado fuera del alcance de estos breves comentarios. 